\title{
Assessment of Uncharred Palm Kernel Shell as a Filter Medium in Low Rate Filtration
}

\author{
Jeje J. O. ${ }^{1, *}$ and Oladepo K. T. ${ }^{1}$ \\ ${ }^{1}$ Department of Civil Engineering, Obafemi Awolowo University, Ile Ife, Nigeria \\ Corresponding Author: *jemails2000@yahoo.co.uk
}

https://doi.org/10.36263/nijest.2021.01.0246

\begin{abstract}
This study examined the use of uncharred palm kernel shells as a filter medium in low rate filtration as a water treatment alternative. The filter column was made of $150 \mathrm{~mm}$ diameter PVC pipe about $1.8 \mathrm{~m}$ high. The filter medium (uncharred palm kernel shells) with size range 0.15 $0.60 \mathrm{~mm}$ overlying two layers of graded gravels. The raw water passed through the filter medium and the effluent collected in a metal tank. The effluent was evaluated by monitoring the flow rate, turbidity, filtration rate, bacteriological quality and headloss across the filter bed for a daily six hour run for 14 days. The filter bed was cleaned using the throwing-over method after the filtration rate became appreciably very low at $1.20 \mathrm{l} / \mathrm{min}-\mathrm{m}^{2}$. It was found from the results obtained that uncharred palm kernel shells could serve as an effective filter for low rate filtration relative to sand. An average hydraulic loading and filtration rate of $120.35 \mathrm{l} / \mathrm{min}-\mathrm{m}^{2}$ and $5.5 \mathrm{l} / \mathrm{min}-\mathrm{m}^{2}$ were achieved respectively. The turbidity of the filtered water reduced below $5.5 \mathrm{NTU}$ after the eleventh day and the bacteriological treatment level though excessively high at 65 coliform/100 $\mathrm{ml}$ showed reducing tendencies $(120 / 100 \mathrm{ml}$ to $65 / 100 \mathrm{ml})$.
\end{abstract}

Keywords: Filtration, Uncharred palm kernel shells, Headloss, Low rate filtration, Potable water

\subsection{Introduction}

The primary aim of the World Health Organization (WHO, 2006) guidelines for drinking water quality is the protection of public health. These guidelines emphasize microbiological safety which is due to the fact that more than half the world's population is still exposed to waters that are not free from pathogenic organisms.

A typical water treatment plant consists of aeration, coagulation and flocculation, sedimentation, filtration, disinfection and distribution units. The treatment is necessitated by the possible presence of some impurities such as dissolved gases, dust, minerals, organic matters, microorganisms and other pollutants (Hammer, 1977).

The slow sand filter was studied in this project and it precludes any chemical pre-treatment as against the rapid sand filter which is mostly used in most treatment plants because of its ability to remove about $99.9 \%$ of the bacteria present if it is not overloaded (Alam et al., 2007). This filtration technique employs the use of the filter medium, uncharred palm kernel shells in this case, as a mechanical and microbiological purifier of water. The mechanical purification is due to the straining effect of the filter medium and the microbiological removal due to the action of a biological layer called the schmutzdecke, which develops on the bed's surface (Rust and McArthur, 1991).

The Schmutzdecke is the layer that provides the effective purification of potable water treatment. It is a gelatinous layer or biofilm called the hypogeal layer or schmutzdecke. This sticky film, which is reddish brown in colour, consists of decomposing organic matter, iron, manganese and silica and therefore acts as a fine filter media that contributes to the removal of turbid particles in the raw water (Buzunis, 1995). It also doubles up as an initial zone of biological activity and providing some degradation of soluble organics in the raw water, which is useful for reducing tastes, odours and colour. It is formed in the first few weeks of operation and consists of organic matter including 
bacteria, fungi, protozoa, rotifer and various aquatic insect larvae. It consists of alluvial mud, organic matter, bacteria, diatoms, zooplankton, thread-like algae formed by the excretion of microorganisms. It is the layer of aquatic life that is responsible for purifying the water (Ranjan and Prem, 2018). As water passes through this biological layer, foreign particles are trapped and essentially eaten by bacteria forms on this layer. As the water slowly passes down through the layers of sand, impurities are left behind, leaving the water between $90 \%$ and $99 \%$ free from bacteria (Elliott et al., 2008; Lee et al., 2014)

Generally, filters operate by the water passing through the sand from top to bottom. Larger suspended particles are left behind in the top layers of sand and the smaller particles of organic sediment left in the sand filter are eaten by microscopic organisms including bacteria and protozoans which stick in the layers of slime that form around the sand particles and the clean water which passes through the filter is safe to drink (Babayemi and Onukwuli, 2016; Uzun et al., 2010). Provided that the grain size is around $0.1 \mathrm{~mm}$ in diameter, a sand filter can remove all faecal coliforms and virtually all viruses (Uzun et al., 2010). Submission of a paper to NIJEST implies that the corresponding author has obtained the permission of all authors, and that all authors have read the paper and guarantee that the paper is an original research work, that the data used in carrying the research will be provided to NIJEST Editors if requested, and that the paper has not been previously published and is not currently under review for publication by another journal.

\subsection{Methodology}

\subsection{Materials}

The filter medium used for the project was uncharred palm kernel shells. The material was sieved though sieves $0.15-0.60 \mathrm{~mm}$. It was bought and milled to the required size ranges using a Hammer mill and pulveriser. The milled and sieved portion was thoroughly washed and rinsed until the water became clear. The materials were then sun-dried, sieved and stored in polythene bags for use. Two layers of gravel, obtained at Opa dam waterworks, were also used for the study.

\subsection{Experimental equipment}

A circular cross sectional filter made of PVC sewer pipe was used. The filter diameter was $150 \mathrm{~mm}$ with a depth of $1800 \mathrm{~mm}$. the surface area was $0.0177 \mathrm{~m}^{2}$. The bottom was sealed with a concrete base and a hole was placed centrally just above the base to collect the effluent from the filter. Headloss and overflow outlets were also made along the sides of the tube; this was to maintain a constant head during filtration. The headloss and sampling ports were made up of 1/8 inches brass pipes with fine mesh wire gauge to prevent the media from blocking the ports.

A manometer and $\mathrm{HACH} 21004$ turbidimeter were also used. The raw water sample was taken from the Opa dam waterworks and the treated water from the dam was used as a control. $19 \mathrm{~mm}$ pipes, gate valves, elbow joints and back nuts were also used.

\subsection{Methods}

The effective sizes (D10) of the uncharred palm kernel shells were determined along with its uniformity coefficients (Gonzalo et al., 2012).

The filter column was placed in the proper position and an inlet pipe, about $5 \mathrm{~cm}$ in size, was placed near the bottom of the pilot column to collect the effluent. The two layers of graded gravel was placed at the bottom and a plug-hole was placed at the bottom. A $750 \mathrm{~mm}$ layer of the prepared uncharred palm kernel shells was placed on top of the plate. The schmutzdecke was developed at the surface of this medium and a flat stone was placed on top to prevent disturbance of the schmutzdecke layer. The outlet and overflow pipes were then inserted (Figure 1). Before the first use, the filter was filled with a solution of $100 \mathrm{mg} / \mathrm{l}$ chlorine, left for 12 hours and emptied through the plug-holes. Clean water was also introduced into the filter from the bottom; this was to remove air bubbles from the medium. 


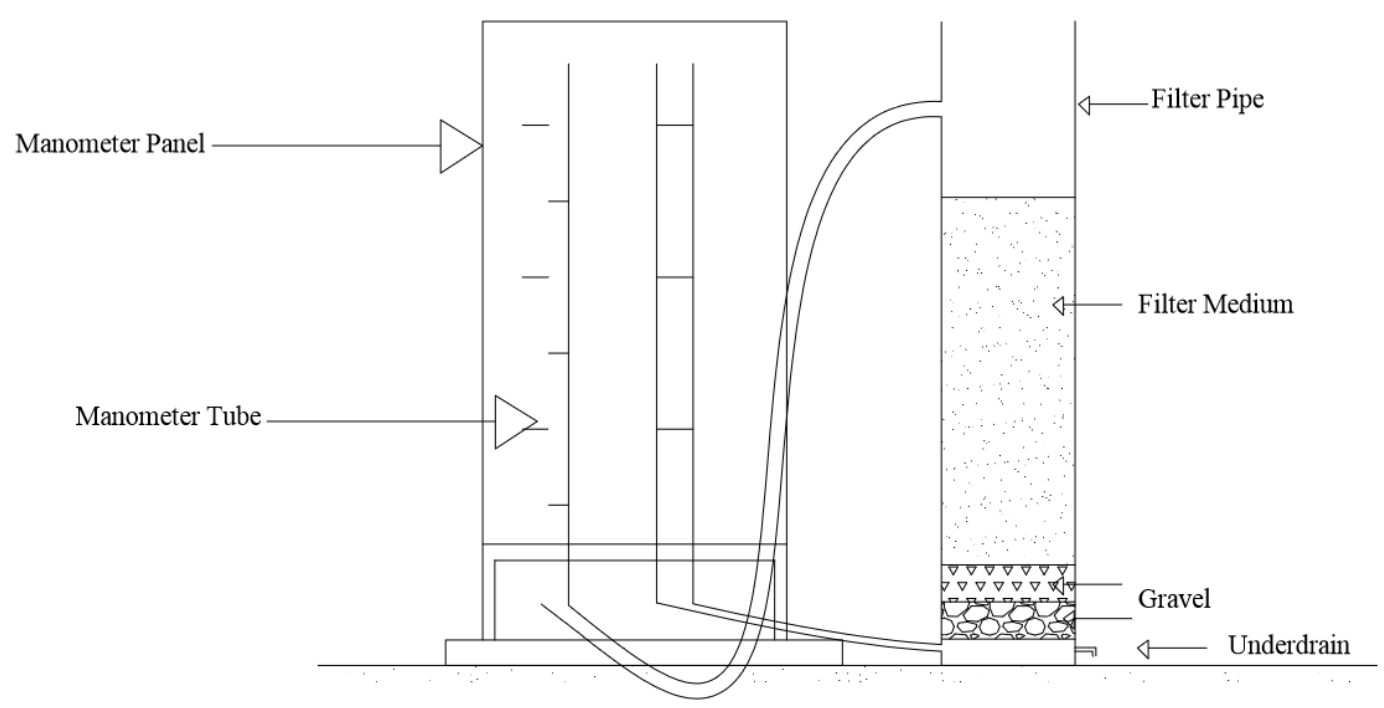

Figure 1: Schematic diagram of filter setup (Babayemi and Onukwuli, 2016)

\subsection{Experimental procedure}

After charging the filter, the influent water was allowed into the filter while a constant head was maintained above the filter head during filtration. The filtration process was started once the tap was closed. The headloss and flow rate was then measured simultaneously. The headloss and flow rate were measured at every two hours interval until the experimental run was terminated. An experimental run terminates when the rate of headloss build up, i.e. pressure drop across the filter, over time reaches an unacceptably high (terminal) headloss and thus the filter bed needs to be cleaned. The filter bed was due for cleaning when the setup reached a flow rate of $1.201 / \mathrm{min}-\mathrm{m} 2$ and the headloss was high. The filter medium was cleaned by reducing the water in the system to about 100 $\mathrm{mm}$ below the top of the filter medium. The top $20 \mathrm{~mm}$ was then scraped off and washed in a flowing steram of water. The entire schmutzdecke layer was not scraped off in order to reduce the ripening period of the new schmutzdecke layer that would be formed. The filter medium and support gravels required additional washing in order to remove dirt particles and to meet the desired cleanliness of less than $0.1 \%$ passing the number 200 screen.

\subsection{Results and Discussion}

\subsection{Headloss and filtration rate}

The filtration rate was set to $6.51 / \mathrm{min}-\mathrm{m} 2$ at the start of the operation and it was observed to decrease with the filtration run time until it became relatively low at $1.2 \mathrm{l} / \mathrm{min}-\mathrm{m} 2$ (Figure 2). The headloss was measured on a daily basis at two hours interval. Figure 3 shows the average daily headloss across the filter medium. It was observed that as the headloss was increasing with time, the filtration rate was also declining with time. The relative headloss standard when treated water was passed into the system was $43 \mathrm{~cm}$ as compared to the net terminal headloss of $117 \mathrm{~cm}$; this shows that the performance of the system had considerably reduced. 


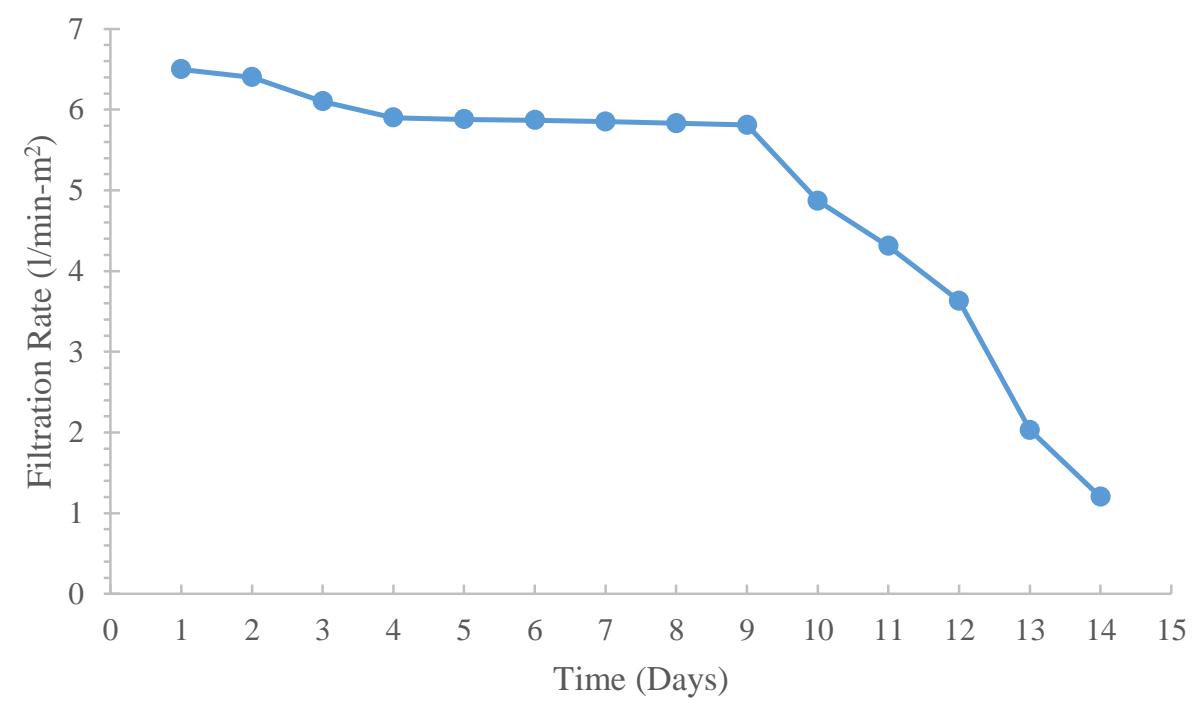

Figure 2: Filtration rate with time

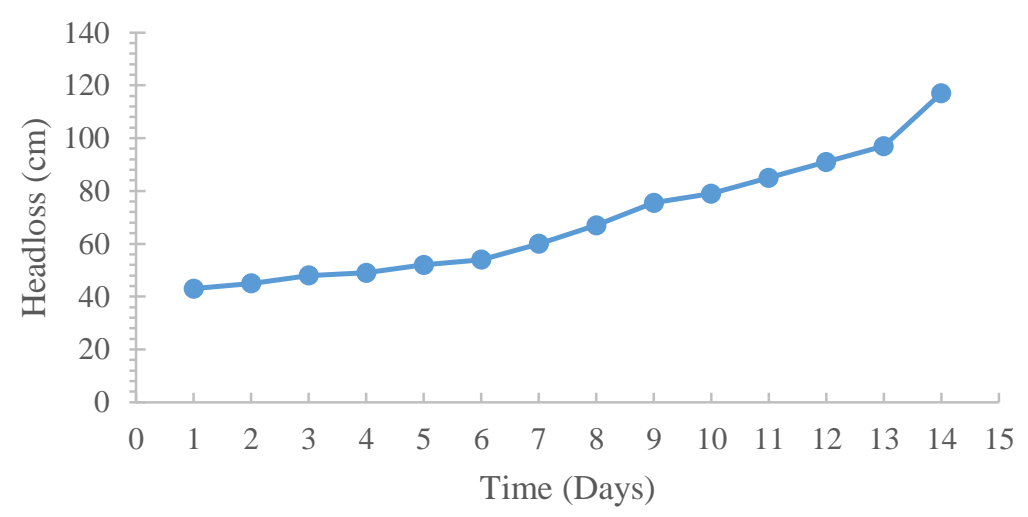

Figure 3: Headloss development with time

\subsection{Turbidity removal and bacteriological analysis}

Figure 4 shows the average daily turbidity removal. It shows the turbidity of the water before filtration and after filtration. It was observed that the rate of turbidity removal with time increased tremendously around the twelfth and fourteenth day.

The schmutzdecke, which is responsible for the bacteriological treatment of the raw water gradually built up as the raw water entered the system. This layer is believed to be responsible for the reduction of coliform count on the thirteenth day (Babayemi and Onukwuli, 2016); the coliform count for raw water was $120 / 100 \mathrm{ml}$ which reduced to $65 / 100 \mathrm{ml}$ after filtration. 


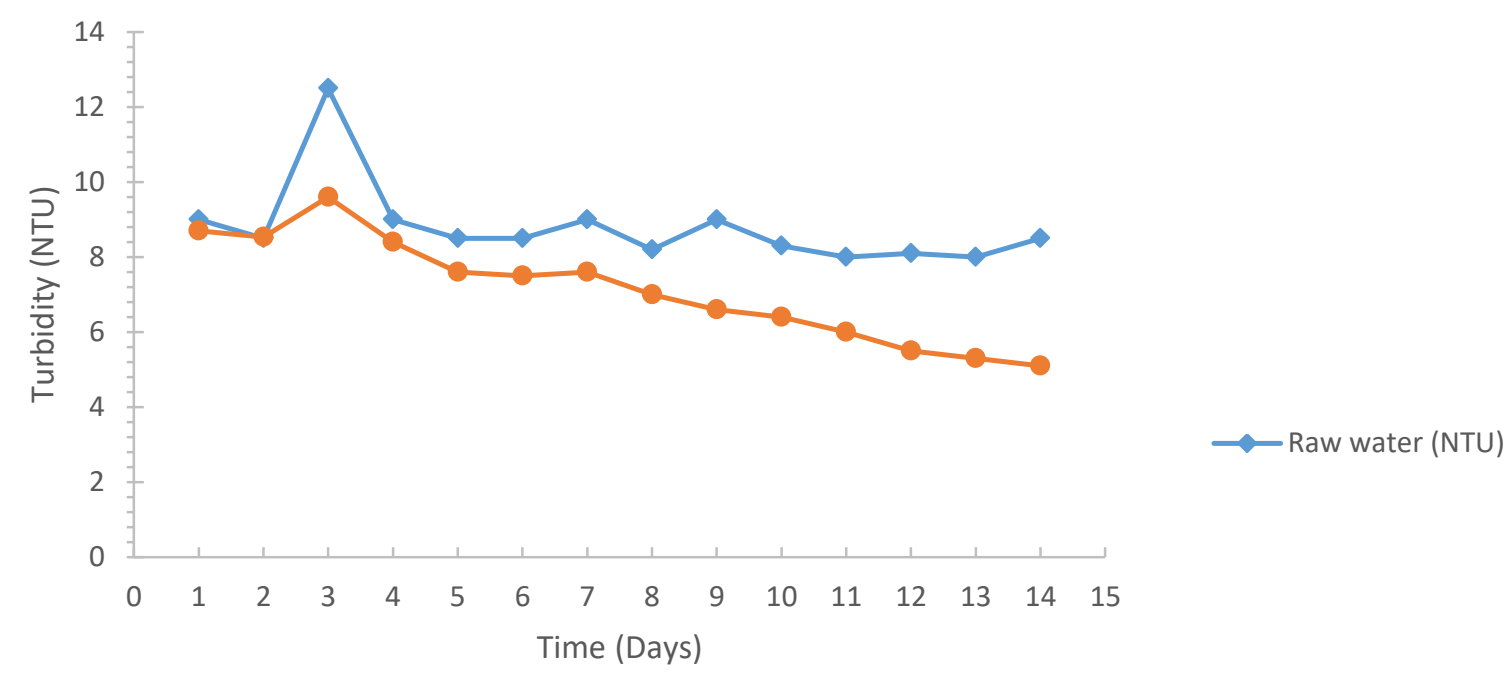

Figure 4: Turbidity removal with time

\subsection{Conclusions}

Based on the singular run carried out, the filtered water maximum turbidity at the time the filter skin is functional was 5.5 NTU, at an average filtration rate of $5.5 \mathrm{l} / \mathrm{min}-\mathrm{m}^{2}$. The volume of filtered water at a bed surface area of $0.0017 \mathrm{~m}^{2}$ and length of run of 14 days is reasonable. The average operational flow rate for this system is $120.50 \mathrm{l} / \mathrm{min}-\mathrm{m}^{2}$ which produced a filtration rate of $5.5 \mathrm{l} / \mathrm{min}-\mathrm{m}^{2}$ at a head of $650 \mathrm{~mm}$. The microbial count is $65 / 100 \mathrm{ml}$.

\section{References}

Alam, M. Z., Muyibi, S. A., Mansor, M. F. and Wahid, R. (2007) Activated carbons derived from oil palm empty-fruit bunches: Application to environmental problems. J. Environ. Sci. 19, pp. 103-108.

Babayemi, A. K. and Onukwuli, O. D. (2016) Adsorption Isotherms, Thermodynamics and Statistical Modeling of Phosphate Removal from Aqueous Solution by Locally prepared Bio-Sorbent. IOSR Journal of Applied Chemistry, 9, pp. 46-50.

Buzunis, B. J. (1995). Intermittently operated slow sand filtration: a new water treatment process. Civil Engineering, University of Calgary

Elliott, M. A., Stauber, C. E., Koksal, F., DiGiano, F. A. and Sobsey, M. D. (2008). Reductions of E. coli, echovirus type 12 and bacteriophages in an intermittently operated household-scale slow sand filter. Water Research, 42(10), pp. 2662-2670.

Gonzalo, V., Olga, M., Sonia, F., Gervasio, A. and Julia, G. A. (2012). Alkaline Pre-treatment of waste chesnut shell from a food industry to enhance cadmium, copper, lead and zinc ions removal. Chemical Engineering Journal, 184, pp. 147-155.

Hammer, M. J. (1977). Water and Wastewater Technology. John Wiley and Sons Inc., New York.

Lee, T., Zubir, Z. A., Jamil, F. M., Matsumoto, A. and Yeoh, F. Y. (2014). Combustion and pyrolysis of activated carbon fibre from oil palm empty fruit bunch fibre assisted through chemical activation with acid treatment. J. Anal. Appl. Pyrolysis. 110, pp. 408-418.

Ranjan, P. and Prem, M. (2018). Schmutzdecke- A Filtration Layer of Slow Sand Filter. International Journal of Current Microbiology and Applied Sciences, 7, pp. 637-645.

Rust, M. and McArthur, K. (1991). Slow sand filtration. Civil Engineering Department, Virginia Tech. 
Uzun, B. B., Apaydin-Varol, E., Ates, F., Ozbay, N. and Putun, A. E. (2010). Synthetic fuel production from tea waste: Characterization of bio-oil and bio-char. Fuel, 89, pp. 176-184.

World Health Organization (2006). Guidelines for drinking-water quality [electronic resource], Incorporating First Addendum. Vol. 1, Recommendations. 3rd ed. 